\title{
Electrochemically Prepared Polypyrroles from Aqueous Solutions
}

\author{
Renyuan QIAN and Jinjin QIU \\ Institute of Chemistry, Academia Sinica, Beijing, China
}

(Received August 17, 1986)

\begin{abstract}
Polypyrrole (PPy) films generated electrochemically from aqueous solutions have been found to have also good electrical conductivity. PPy films with the counter anions $\mathrm{TsO}^{-}, \mathrm{SO}_{4}^{=}$, and $\mathrm{NO}_{3}^{-}$showed compact structure with apparent densities close to their flotation densities. The oxidative stability of PPy films has been compared by the value of the oxidation peak $E_{\mathrm{pa}}$ around $1.0 \mathrm{~V}$ ( $v s$. SCE) in the cyclovoltammogram. Prolonged electrolysis at $+0.8 \mathrm{~V}$ led to oxidative degradation. The temperature dependence of the conductivity followed the variable range hopping equation. However voltage shorted compaction (VSC) conductivity measurements might show pronounced differences at low temperatures for some of these films. No significant frequency dependence of the conductivity was found up to $35 \mathrm{GHz}$. In the IR spectra of electrochemically reduced PPy film by transmission the $v(\mathrm{~N}-\mathrm{H})$ and $s p^{2} v(\mathrm{C}-\mathrm{H})$ absorption bands were observed with no $s p^{3} v(\mathrm{C}-\mathrm{H})$ bands. On grinding the reduced film with $\mathrm{KBr}$ to make powder compact the $s p^{3}$ $v(\mathrm{C}-\mathrm{H})$ absorption bands appeared indicating a mobile proton on the $\mathrm{N}$-atom of the pyrrole ring. Definite evidence from IR spectra for the de-intercalation of the counter anion of the conducting PPy film during electrochemical reduction and chemical compensation has been obtained. The intercalation and de-intercalation of the counter anions was found to be accompanied by profound morphological changes. Molecular composites from in situ polymerization of aqueous pyrrole solution in a flexible polymer are briefly discussed.

KEY WORDS Conducting Polymer / Polypyrrole / Electrochemical Polymerization / Morphology / Chain Structure / Intercalation /
\end{abstract}

Although Dall'Olio et al..$^{1}$ electrochemically polymerized pyrrole in aqueous $\mathrm{H}_{2} \mathrm{SO}_{4}$ even long before conducting polymers became of wide interest, conducting polypyrrole (PPy) have usually been prepared from acetonitrile solution. ${ }^{2}$ Recently it was found that pyrrole could be electrochemically polymerized and intercalated in aqueous solution with various types of counter anions to give PPy films of good conductivity, including detergent anions as $n$-alkyl sulfates, sulfonates, ${ }^{3}$ alkyl aryl sulfonates, ${ }^{4}$ tosylate anion, ${ }^{4}$ and polymeric anions as polyvinyl sulfate and polystyrene sulfonate, ${ }^{5}$ polymethacrylate, and sulfonated polyvinyl alcohol ${ }^{6}$ as the counter anion. In our laboratory we found that with $\mathrm{SO}_{4}^{-}, \mathrm{NO}_{3}^{-}$, and $\mathrm{TsO}^{-}$as the counter anions we can get com- pact conducting PPy films containing less than $20 \%$ void volume, other counter anions gave films of $70-85 \%$ void. $^{7,8}$ In this paper results of our recent investigation ${ }^{9}$ on these dense conducting PPy films are summarized including morphology, oxidative stability, metallic conduction, chain structure, deintercalation and re-intercalation of the counter anions. A brief account for the molecular composites containing PPy is also given.

\section{MORPHOLOGY AND DENSITY}

Conducting PPy films with $\mathrm{ClO}_{4}^{-}, \mathrm{BF}_{4}^{-}$, and $\mathrm{PF}_{6}^{-}$as the counter anion show a morphology of hollow bowls of $20-30 \mu \mathrm{m}$ diameter and consequently have very low apparent density 


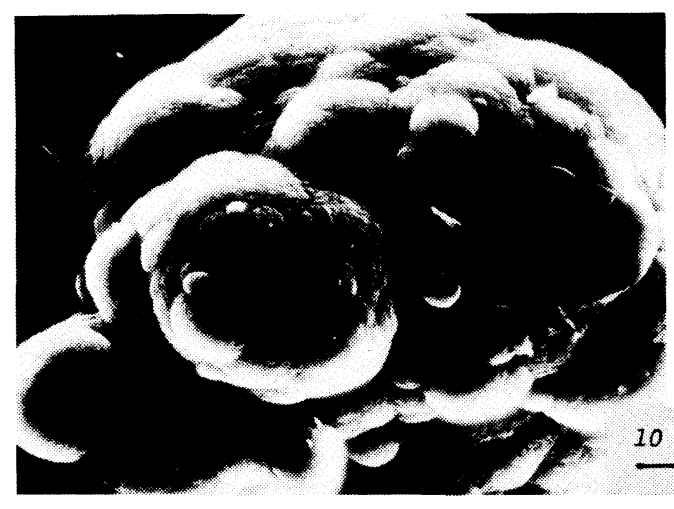

a

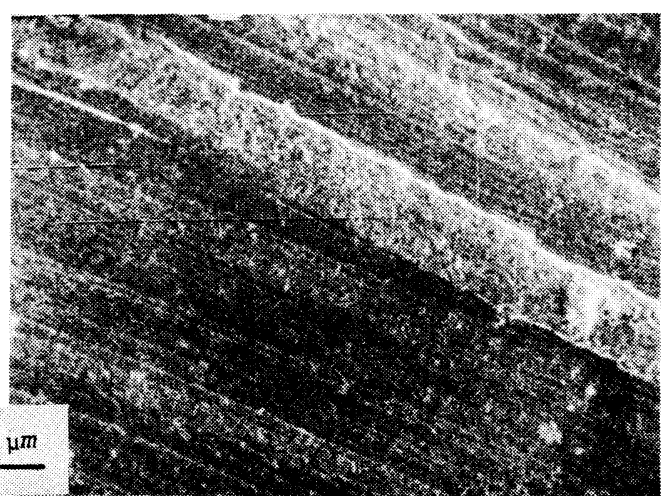

b

Figure 1. SEM photographs of $\mathrm{TsO}^{-}$intercalated PPy film. a, facing the electrolyte; $b$, facing the Pt electrode.

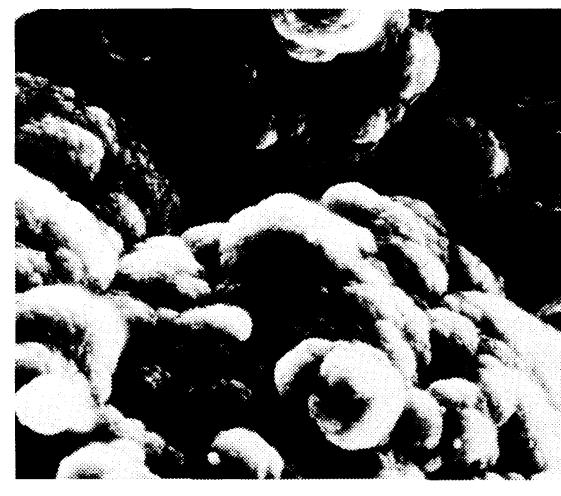

a

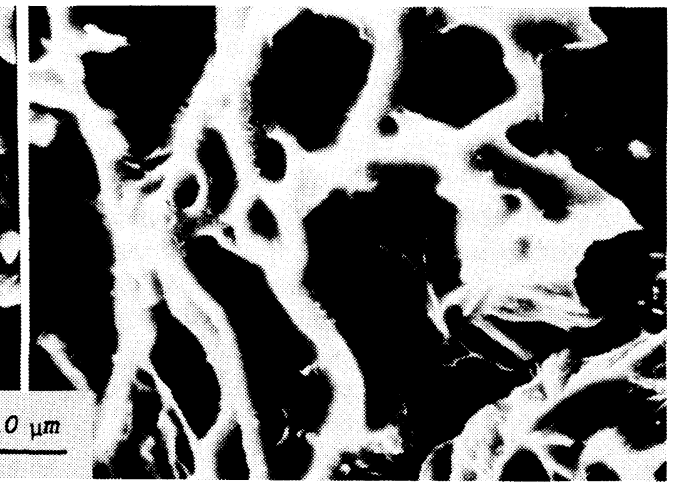

b

Figure 2. SEM photographs of $\mathrm{ClO}_{4}^{-}$intercalated PPy film. a, facing the electrolyte; $b$, facing the $\mathrm{Pt}$ electrode.

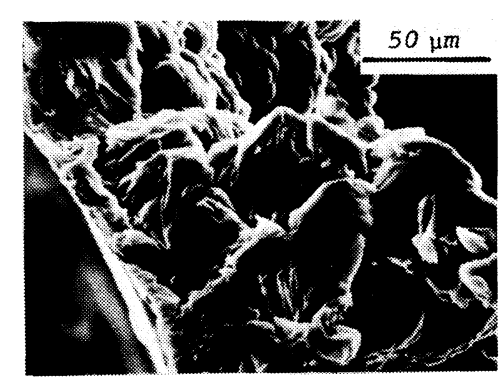

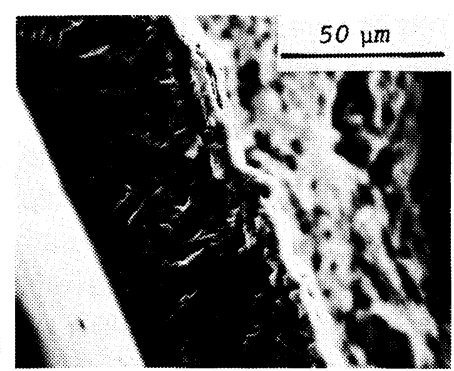

b

Figure 3. SEM photographs of the fracture surface of (a) $\mathrm{TsO}^{-}$(b) $\mathrm{SO}_{4}^{=}$intercalated $\mathrm{PPy}^{-}$films.

as calculated from the dimensions and mass of the film electrochemically prepared either from acetonitrile solution or from aqueous solution. ${ }^{7}$ The morphology is controlled by the nature of the counter anion rather than the nature of the solvent used in electrolysis. The contrast of the morphology of $\mathrm{TsO}^{-}$intercalated PPy film against that of $\mathrm{ClO}_{4}^{-}$interca- 
Table I. Densities of anion intercalated PPy films at $20.0^{\circ} \mathrm{C}$ prepared electrochemically from aqueous solutions

\begin{tabular}{|c|c|c|c|c|}
\hline \multirow{2}{*}{$\begin{array}{l}\text { Supporting } \\
\text { electrolyte }\end{array}$} & \multirow[t]{2}{*}{$\mathrm{Scm}^{-1}$} & \multirow{2}{*}{$\begin{array}{c}\begin{array}{c}\text { Flotation } \\
\text { density }\end{array} \\
\mathrm{g} \mathrm{cm}^{-3}\end{array}$} & \multirow{2}{*}{$\frac{\begin{array}{c}\text { Apparent } \\
\text { density }\end{array}}{\mathrm{gcm}^{-3}}$} & \multirow{2}{*}{$\%$ void $^{a}$} \\
\hline & & & & \\
\hline $\mathrm{HClO}_{4}$ & $20-30$ & 1.575 & 0.52 & 67 \\
\hline $\mathrm{NaClO}_{4}$ & - & 1.558 & 0.36 & 77 \\
\hline $\mathrm{NaBF}_{4}$ & 12 & 1.540 & 0.38 & 73 \\
\hline $\mathrm{KPF}_{6}$ & 12 & 1.549 & 0.46 & 70 \\
\hline $\mathrm{TsOH}$ & $60-200$ & 1.368 & 1.24 & 9 \\
\hline TsONa & $60-200$ & 1.364 & 1.25 & 8 \\
\hline $\mathrm{NaNO}_{3}$ & $4-30$ & 1.516 & 1.25 & 18 \\
\hline $\mathrm{H}_{2} \mathrm{SO}_{4}$ & 10 & $1.532\left(1.514^{\mathrm{b}}\right)$ & $1.26\left(1.50^{\mathrm{b}}\right)$ & $18\left(1^{\mathrm{b}}\right)$ \\
\hline $\mathrm{Na}_{2} \mathrm{SO}_{4}$ & $15-20$ & 1.524 & 1.27 & 17 \\
\hline $\mathrm{KCl}$ & 46 & - & - & - \\
\hline $\mathrm{KBr}$ & 21 & - & - & - \\
\hline $\mathrm{K}_{3} \mathrm{Fe}(\mathrm{CN})_{6}$ & 19 & - & - & - \\
\hline
\end{tabular}

a Calculated from flotation and apparent densities.

b Another set of data. ${ }^{7}$

lated one is shown in Figures 1 and 2. They are both constructed of $1 \mu \mathrm{m}$ or less diameter particles aggregated into the form of a califlower but the former is densely packed while the latter is hollow as easily seen from the film surface facing the Pt electrode used in electrolysis. In the former case the surface facing the electrode is smooth enough to reproduce the surface scratches on the electrode surface. The film polymerized in $\mathrm{Na}_{2} \mathrm{SO}_{4}$ is even more compact than that polymerized in TsONa as revealed in the SEM photographs of the fracture surfaces shown in Figure 3.

The flotation density determined at $20.0^{\circ} \mathrm{C}$ in a density gradient column made of 1,2dibromoethane/hexane mixtures of density values 1.40 and $1.70 \mathrm{~g} \mathrm{~cm}^{-3}$ and the apparent density calculated from the area and thickness and the mass of the film are listed in Table I for PPy films of various counter anions prepared from aqueous solutions. The $\mathrm{TsO}^{-}$intercalated PPy film has smaller flotation density than other anion intercalated PPy, presumably due to the length of the non-spherical $\mathrm{TsO}^{-}$ ion.

\section{OXIDATIVE STABILITY}

When an intercalated PPy film is put into the same supporting electrolyte solution as the film was electrochemically generated and cyclovotammogram is run, an oxidation peak will be observed on the first scant at $E_{\mathrm{pa}}$ values around $1 \mathrm{~V} v s$. SCE depending on the intercalated anion. ${ }^{10}$ The peak current $i_{\mathrm{pa}}$ has been found to be proportional to the value of $\mathrm{mC} \mathrm{cm}^{-2}$ from which the intercalated PPy film was made. No reduction peak could be identified during the back scan, and on the second scan cycle the oxidation peak current becomes very small and $E_{\mathrm{pa}}$ shifts to lower values. The oxidation peak will vanish completely on subsequent scans. These facts indicate that an irreversible oxidation is occurring during the cyclovoltammetry beyond $+1 \mathrm{~V}$. Similar conclusion was arrived by Asavapiriyanont ${ }^{11}$ using $\mathrm{KNO}_{3}$ as the supporting electrolyte. The values of $E_{\mathrm{pa}}$ for intercalated PPy films of $10 \mathrm{mC} \mathrm{cm}^{-2}$ made from $\mathrm{TsOH}, \mathrm{TsONa}$, $\mathrm{H}_{2} \mathrm{SO}_{4}$, and $\mathrm{Na}_{2} \mathrm{SO}_{4}$ solutions are 1.13, 0.99, 1.07 , and $0.96 \mathrm{~V}$ respectively at a potential scan rate of $50 \mathrm{mV} \mathrm{s}^{-1}$. When $\mathrm{TsO}^{-}, \mathrm{NO}_{3}^{-}$, and 


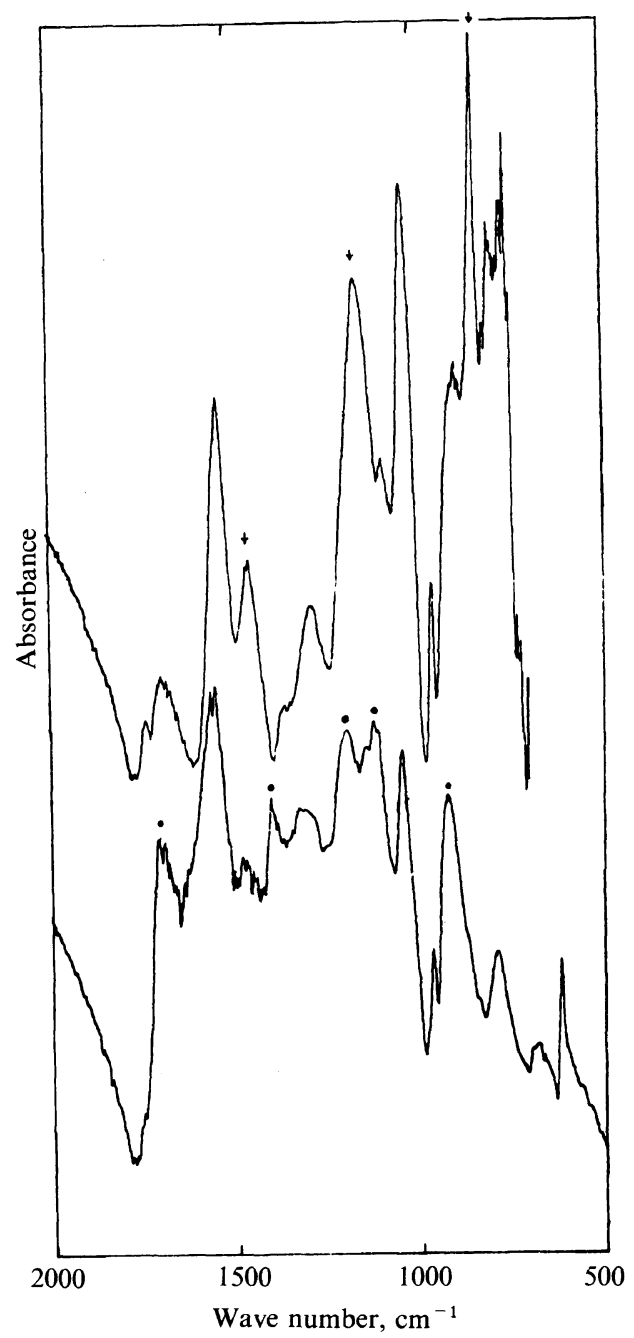

Figure 4. IR spectrum of a $\mathrm{SO}_{4}^{=}$intercalated PPy film maintained in $\mathrm{Na}_{2} \mathrm{SO}_{4}$ solution at $+0.8 \mathrm{~V}$ vs. SCE for $2 \mathrm{~h}$ (lower curve) as compared to that of an ordinary $\mathrm{SO}_{4}^{=}$ intercalated PPy film (upper curve). Dots indicate the new bands or bands with enhanced intensity. Arrows indicate bands with reduced intensity in the lower curve.

$\mathrm{SO}_{4}^{=}$intercalated PPy films are put into aqueous solutions of their corresponding electrolytes and a constant potential of $0.8 \mathrm{~V}$ is applied for a duration of $1-2 \mathrm{~h}$, the films will become brittle with their conductivities being dropped significantly and the solutions turn to pink to brown, presumably due to the presence of oligomers disintegrated from the film during the oxidation process. The IR spectrum of a

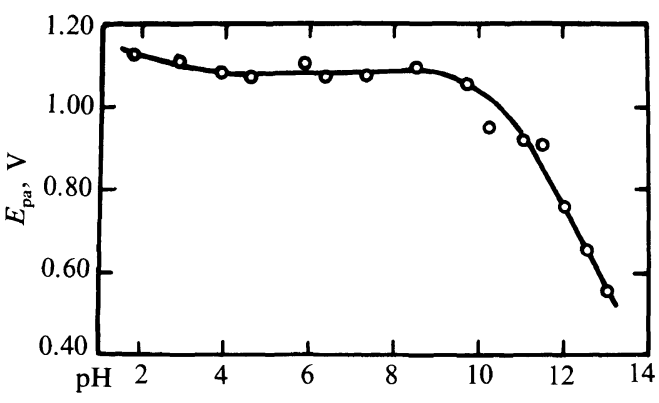

Figure 5. Effect of $\mathrm{pH}$ of the solution containing $0.1 \mathrm{M}$ $\mathrm{TsO}^{-}$ion on the value of $E_{\mathrm{pa}}$ of cyclovoltammogram of $\mathrm{TsO}^{-}$intercalated PPy film.

$\mathrm{SO}_{4}^{=}$intercalated PPy film polymerized from $\mathrm{Na}_{2} \mathrm{SO}_{4}$ solution maintained at $0.8 \mathrm{~V}$ for $2 \mathrm{~h}$ is shown in Figure 4. As compared to the spectrum of usual $\mathrm{SO}_{4}^{=}$intercalated PPy film the intensities of the absorption bands at 1466 and $1178 \mathrm{~cm}^{-1}$ are very much reduced, while the absorption band at $1697 \mathrm{~cm}^{-1}$, which is $v(\mathrm{C}=\mathrm{O})$ absorption in the oxidized product, is much enhanced and new bands at 1198 and $1117 \mathrm{~cm}^{-1}$ appear with considerable intensities. Thus we are quite sure that the electrochemical oxidation peak $E_{\mathrm{pa}}$ around $1 \mathrm{~V}$ leads to chemical oxidation accompanied by some degradation of the PPy chain. This $E_{\mathrm{pa}}$ value could be considered as a criterion for oxidative stability of the intercalated PPy film, lower $E_{\mathrm{pa}}$ values indicating less oxidative stability. So, for the same intercalated anion the PPy film made in a neutral solution has lower oxidative stability than that made in an acid solution.

For accessing some idea about the relative oxidative stability of conducting PPy in solutions of various $\mathrm{pH}$ values a $\mathrm{TsO}^{-}$intercalated PPy film of $10 \mathrm{mC} \mathrm{cm}^{-2}$ is put into a $0.1 \mathrm{M} \mathrm{TsOH}$ solution with the solution $\mathrm{pH}$ adjusted by means of Britton-Robinson buffer (pH 1.5-12) or adding $\mathrm{NaOH}$ solution $(\mathrm{pH}>12)$ and the cyclovoltammogram is run on the first scan at $50 \mathrm{mV} \mathrm{s}^{-1}$. The $E_{\mathrm{pa}}$ values obtained $^{8}$ in solutions of $\mathrm{pH} 1.5$ to 13 are shown in Figure 5. Evidently the $\mathrm{TsO}^{-}$intercalated PPy film has good oxidative stability 


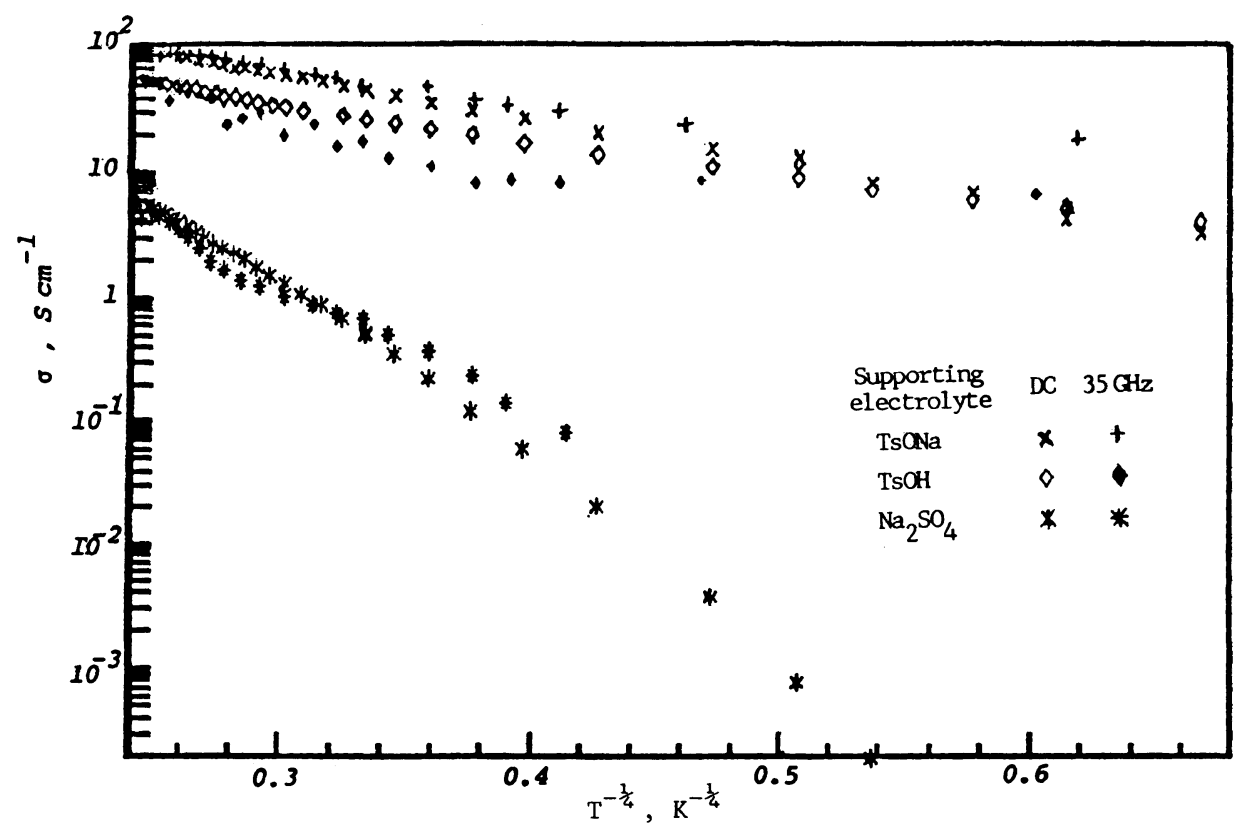

Figure 6. Temperature dependence of the conductivities of intercalated PPy films.

in acidic and neutral solutions while the stability deteriorated steadily beyond $\mathrm{pH} 9$. Similar results are observed with $\mathrm{SO}_{4}^{=}$intercalated PPy film.

\section{THE METALLIC CONDUCTIVITY}

All conducting polymers show a decrease in conductivity with decreasing temperature characteristic of a semi-conductor when measured by the ordinary 4-probe method. In most cases the conductivity-temperature relationship follows closely the so called variable range hopping relation ${ }^{12}$ over rather wide temperature ranges:

$$
\log \left(\sigma T^{1 / 2}\right)=A-B T^{-1 / 4}
$$

Thus a plot of $\log \left(\sigma T^{1 / 2}\right)$ or simply $\log \sigma v s$. $T^{-1 / 4}$ gives a straight line as shown in Figure 6 for intercalated PPy films prepared from aqueous solutions. ${ }^{13}$ Also shown in the figure is the frequency independence of the conductivity behavior from $\mathrm{DC}$ to $35 \mathrm{GHz}$ in the microwave region.
The only direct evidence for metallic conduction for PPy and conducting polymers in general comes from the thermopower measurements. The Seebeck coefficient $S$ at low temperatures is proportional to the absolute temperature passing through the origin on $S-T$ plot, the value of $S$ being a few $\mu \mathrm{V} \mathrm{K}^{-1}$, typical of metals, as shown in Figure 7 for the same samples as in Figure 6. For organic semi-conductors the value of $S$ lies between $10^{2}-10^{3} \mu \mathrm{V} \mathrm{K}^{-1}$. For some time we have suggested that in ordinary 4-probe conductivity measurement the conductivity behavior observed is masked by the intergranular or interfibrillar contact resistance because of the heterogeneous morphological structure of the conducting polymers. We adopted the voltage-shorted compaction (VSC) method of conductivity measurement for polycrystalline powder compactions ${ }^{14,15}$ to conducting polymers. ${ }^{16,17}$ VSC conductivity data do actually show an increase of conductivity with deereasing temperature typical of metals, as shown in Figure 8 for $\mathrm{TsO}^{-}$, 


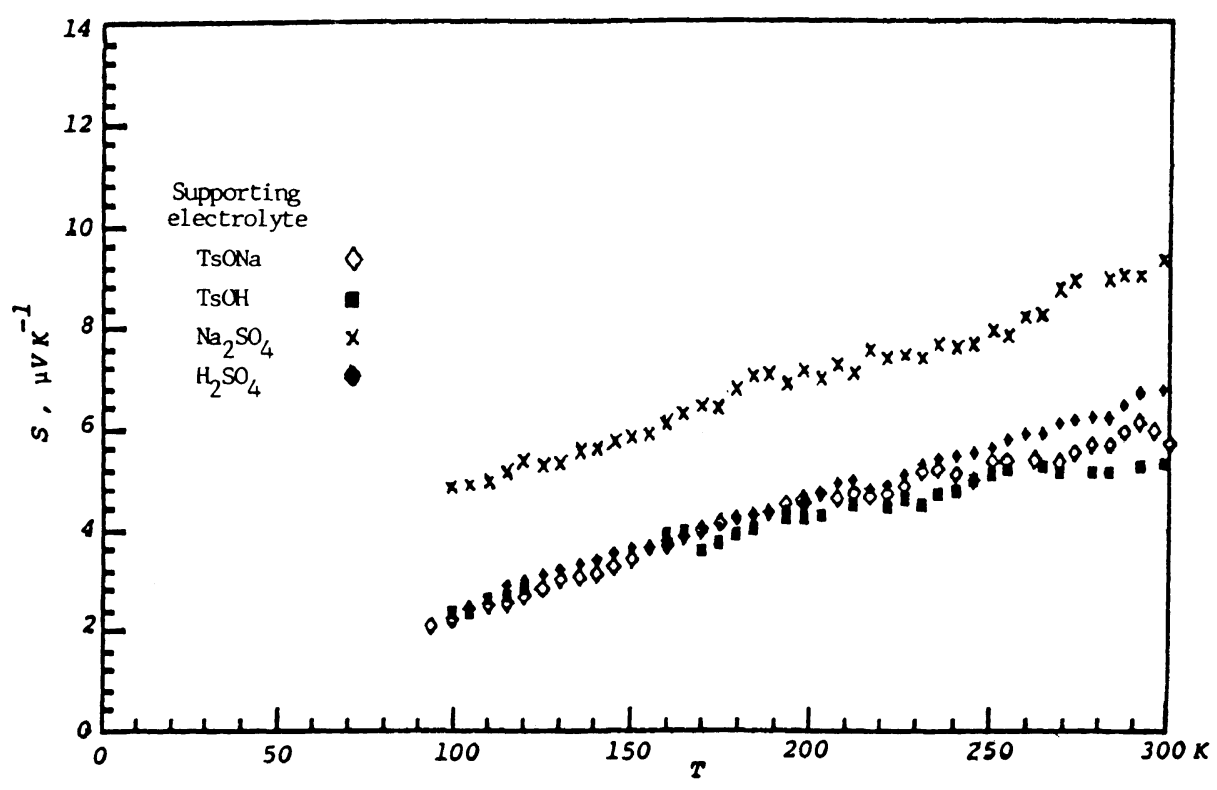

Figure 7. Temperature dependence of the Seebeck coefficients of intercalated PPy films.

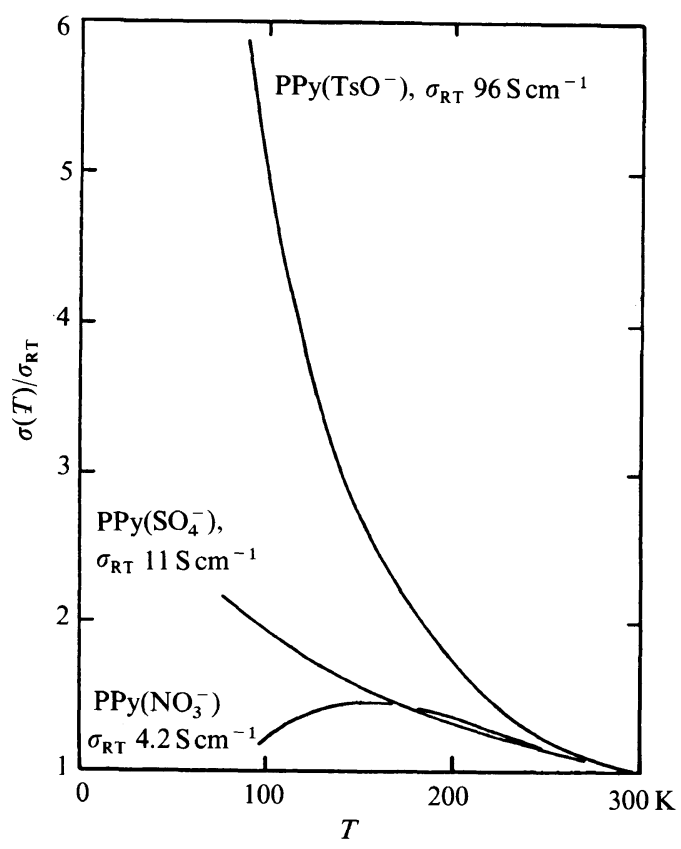

Figure 8. VSC curves of the intercalated PPy films.

$\mathrm{SO}_{4}^{=}$, and $\mathrm{NO}_{3}^{-}$intercalated PPy films. ${ }^{8}$ PPy films of higher room temperature conductivity usually show a more pronounced increase of conductivity with decreasing temperature. PPy films of lower conductivity in some cases show a broad maximum at low temperature, ${ }^{8,17}$ although no much difference in conductivity behavior could be detected at all by 4-probe measurements. We believe that VSC measurement can actually reveal some aspects of the intrinsic conductivity behavior of conducting polymers. In view of such considerations the intrinsic conductivity of conducting polymers must be very much higher. than the values we now usually assume from 4-probe measurements. In VSC measurement the specimen between two voltage measuring terminals is short circuited by a thin coating of $\mathrm{Ag}$ paste, so the absolute value of conductivity of the sample can no longer be evaluated while the temperature dependence of its conductivity is reflected in the VSC curve observed as a closer analysis of the situation has shown. ${ }^{15}$ In applying $\mathrm{Ag}$ paste to the specimen it must be very careful so that the Ag coating on the surface must be very thin yet the paste penetrates into the specimen to some depth. 


\section{CHEMICAL STRUCTURE OF PPy CHAIN}

The pyrrole units in a PPy chain are mainly $\alpha, \alpha^{\prime}$-linked from the evidence obtained in $\mathrm{IR}^{2}$ and solid state NMR. ${ }^{18}$ The mol mass and its distribution are so far inaccessible experimently because of its insolubility. Some puzzling facts about the chemical structure of PPy chain remain not understood.

Elemental analysis of intercalated PPy always shows an excess of $\mathrm{H}$ in the mol ratios $\mathrm{C}: \mathrm{H}: \mathrm{N}$ and a considerable amount of $\mathrm{O}$ in the sample as shown in Table II. The amount of $\mathrm{O}$ content in the sample cannot be simply attributed to oxidation to form $\mathrm{C}=\mathrm{O}$ groups which would give a strong IR absorption band around $1700 \mathrm{~cm}^{-1}$. In the IR spectra of PPy films, however, only weak absorption is observed, and in the cases of PPy from $\mathrm{NaNO}_{3}$, TsONa, and $\mathrm{K}_{3} \mathrm{Fe}(\mathrm{CN})_{6}$, for example, $v$ $(\mathrm{C}=\mathrm{O})$ absorption is barely noticeable as shown in Figure 9. We suppose that $\mathrm{O}$ in conducting PPy is mainly present in the form of charge transfer complex between $\mathrm{O}_{2}$ molecules or atoms with the pyrrole units. It is also interesting to point out here that when $\mathrm{K}_{3} \mathrm{Fe}(\mathrm{CN})_{6}$ is used as the supporting electrolyte during electrochemical polymerization of pyrrole, the anion intercalated in the film is $\mathrm{Fe}(\mathrm{CN})_{6}^{4-}$ instead of $\mathrm{Fe}(\mathrm{CN})_{6}^{3-}$ as evident from the IR spectrum. During the charge transfer intercalation the counter anion is quite often reduced to lower valence state.

The excess amount of $\mathrm{H}$ could not be accounted for by the possible presence of pyrrolidone end groups as the oxidation product. ${ }^{19}$ For intercalated PPy films because of rather intense IR absorption bands their IR spectra are usually taken on $\mathrm{KBr}$ powder compacts which show no $v(\mathrm{~N}-\mathrm{H})$ and $s p^{2} v$ $(\mathrm{C}-\mathrm{H})$ absorptions while $s p^{3} v(\mathrm{C}-\mathrm{H})$ absorption bands at $2850-2940 \mathrm{~cm}^{-1}$ appear instead. For electrochemically reduced PPy films, which have conductivities usually less than $10^{-6} \mathrm{~S} \mathrm{~cm}^{-1}$, we have been able to get
Table II. Elemental analysis of intercalated PPy films electrochemically prepared from aqueous solutions, $\mathrm{PPy}^{\mathrm{y}+}\left(y \mathrm{X}^{-}\right)$

\begin{tabular}{|c|c|c|c|c|c|}
\hline $\begin{array}{l}\text { Supporting } \\
\text { electrolyte }\end{array}$ & $\mathrm{C}$ & $\mathrm{H}$ & $\mathrm{N}$ & $y$ & $\mathrm{O}^{\mathrm{a}}$ \\
\hline $\mathrm{TsOH}$ & 4 & 3.54 & 0.95 & 0.31 & 0.44 \\
\hline TsONa & 4 & 3.44 & 1.00 & 0.31 & 0.40 \\
\hline $\mathrm{H}_{2} \mathrm{SO}_{4}$ & 4 & 3.35 & 0.97 & 0.19 & 0.68 \\
\hline $\mathrm{Na}_{2} \mathrm{SO}_{4}$ & 4 & 3.34 & 0.96 & 0.12 & 0.65 \\
\hline $\mathrm{NaNO}_{3}$ & 4 & 3.24 & $1^{\mathrm{b}}$ & 0.19 & 0.84 \\
\hline
\end{tabular}

a From balance.

b Assumed.

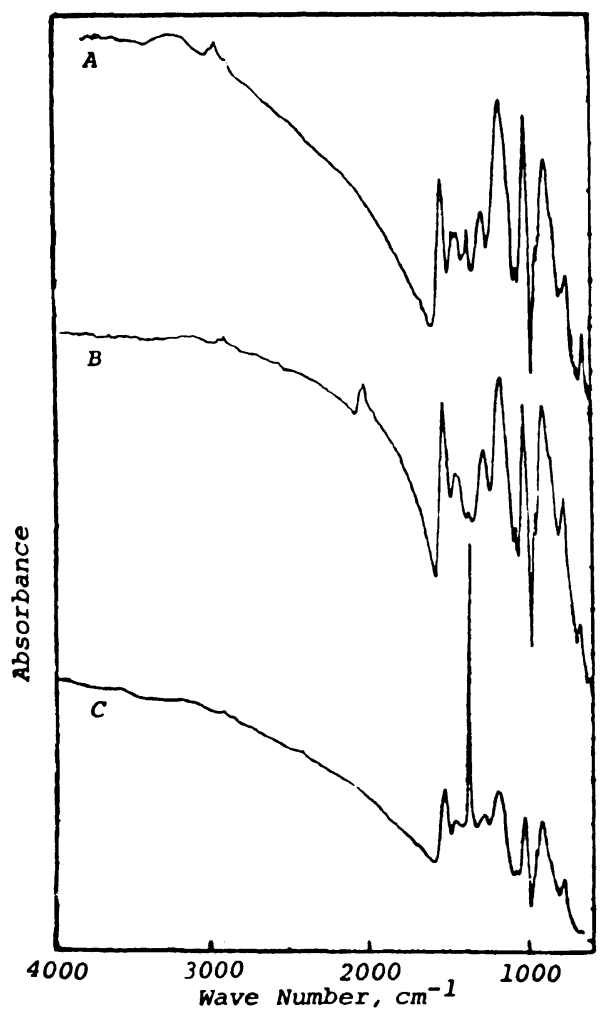

Figure 9. IR spectra of $\mathrm{TsO}^{-}(\mathrm{A}), \mathrm{Fe}(\mathrm{CN})_{6}^{4-}$ (B), and $\mathrm{NO}_{3}^{-}$(C) intercalated PPy films by $\mathrm{KBr}$ powder compacts.

direct transmission IR measurement on thin films which show clearly the presence of $v$ $(\mathrm{N}-\mathrm{H})$ band at $3450 \mathrm{~cm}^{-1}$ and $s p^{2} v(\mathrm{C}-\mathrm{H})$ band at $3105 \mathrm{~cm}^{-1}$ and the absence of $s p^{3} v$ (C-H) absorption as shown in Figure 10. However, it is interesting enough that on 


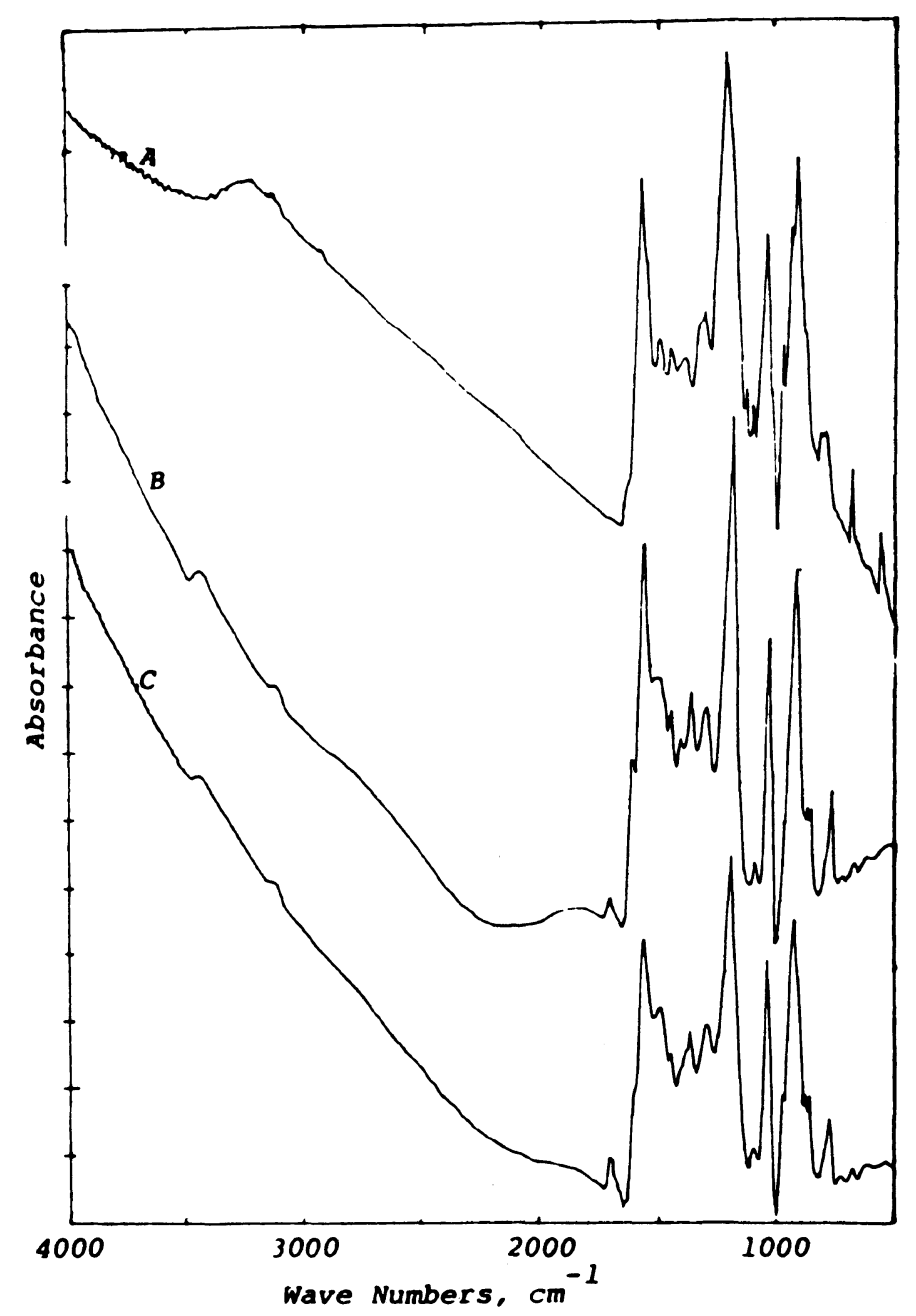

Figure 10. IR spectra of electrochemically reduced $\mathrm{PPy}$ films by transmission. $\mathrm{A}$, from $\mathrm{SO}_{4}^{=}$intercalated PPy; B, from $\mathrm{NO}_{3}^{-}$intercalated PPy; C, from $\mathrm{TsO}^{-}$intercalated PPy.

grinding the reduced PPy film with $\mathrm{KBr}$ to make powder compact the $s p^{3} v(\mathrm{C}-\mathrm{H})$ bands re-appear in its IR spectrum as shown in Figure 11. Presumably a charge transfer intercalation of $\mathrm{Br}^{-}$takes place during grinding neutral PPy with $\mathrm{KBr}$. This suggests a reversible structure change involving the mobile proton from $\mathrm{N}$ to $\beta$-C atom in the pyrrole unit during the charge transfer intercalation process:<smiles>[Y]C1=[N+]C(C)=CC=C1C</smiles>

This reversible shift of $\mathbf{H}$ does not explain the excess $\mathrm{H}$ present in intercalated PPy films. At the moment it appears not clear from where the growing PPy chain picks up the excess $\mathrm{H}$ atoms, from the $\mathrm{H}$ atoms split off during anodic polymerization or from the solvent. To maintain a conjugated chain, as necessi- 


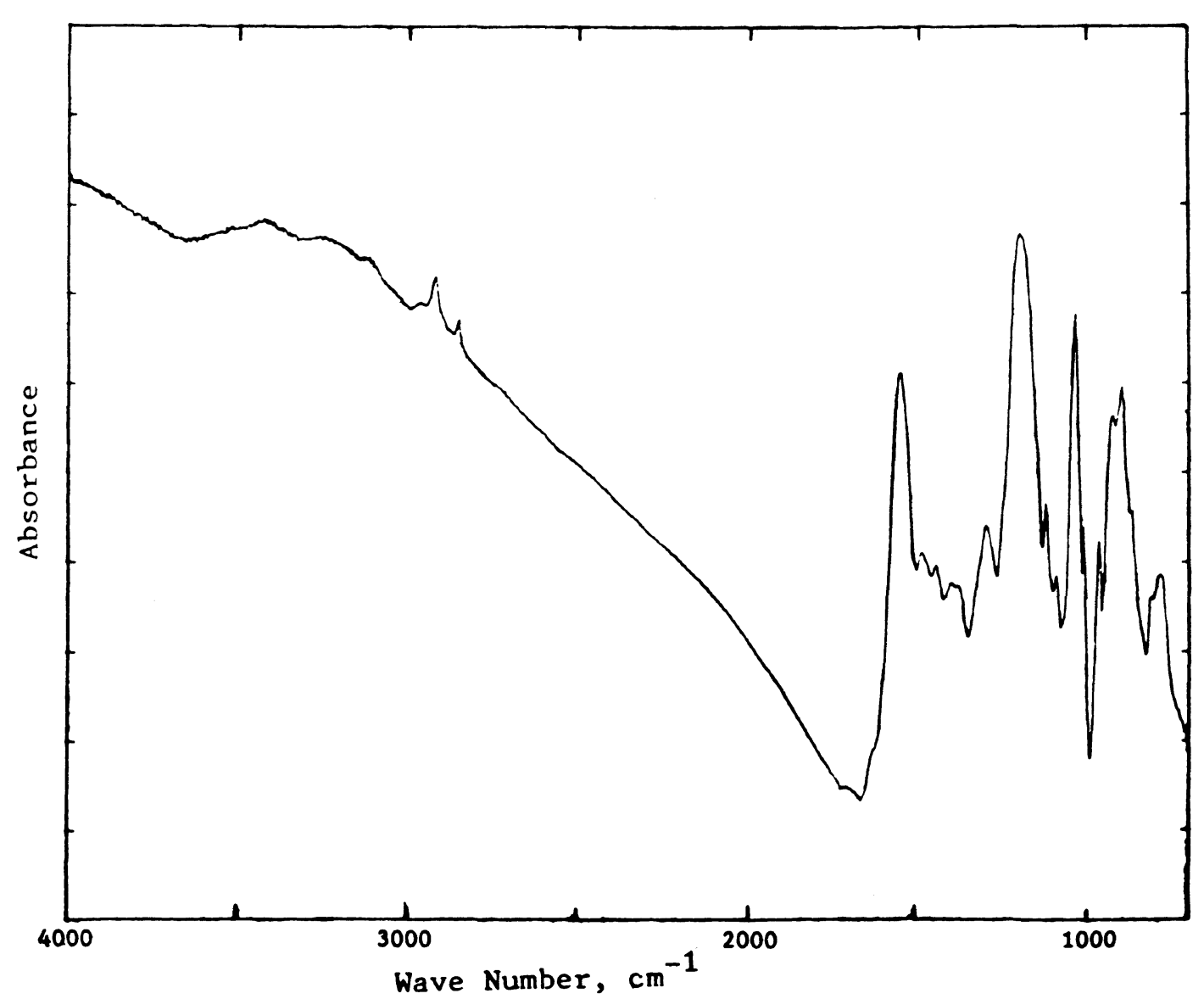

Figure 11. IR spectrum of $\mathrm{KBr}$ compact of an electrochemically reduced $\mathrm{PPy}$ from $\mathrm{TsO}^{-}$intercalated PPy film.

tated by good conductivity, with more than $3 \mathrm{H}$-atoms per pyrrole unit, a possible structure would involve the presence of the structural units of<smiles>CC1=[NH+]C(=C(C)C)C(C(C)(C)C)=C1C(C)(C)C</smiles>

This is however only a speculation. Further work has to be done.

\section{DE-INTERCALATION AND RE-INTERCALATION}

The terms "doping," "de-doping," and "compensation" were borrowed from semiconductor technology. The nature of these processes remains not entirely clear. We have taken the advantage of a very strong and sharp IR absorption band $v(\mathrm{~N}-\mathrm{O})$ at $1384 \mathrm{~cm}^{-1}$ present in a $\mathrm{NO}_{3}^{-}$intercalated PPy film to follow the electrochemical reduction and reoxidation processes and the chemical compensation process by $\mathrm{NH}_{4} \mathrm{OH}$ or $\mathrm{NaOH}$ solution treatment. The electrochemically prepared PPy from $\mathrm{NaNO}_{3}$ solution shows clearly the $v(\mathrm{~N}-\mathrm{O})$ absorption band indicating the intercalated $\mathrm{NO}_{3}^{-}$ion in the film. There have been reports of the absence of $\mathrm{ClO}_{4}^{-}$absorption in PPy films prepared electrochemically from $\mathrm{CH}_{3} \mathrm{CN}$ solution with $\mathrm{Bu}_{4} \mathrm{NClO}_{4}$ as sup- 
R. QIAN and J. QIU

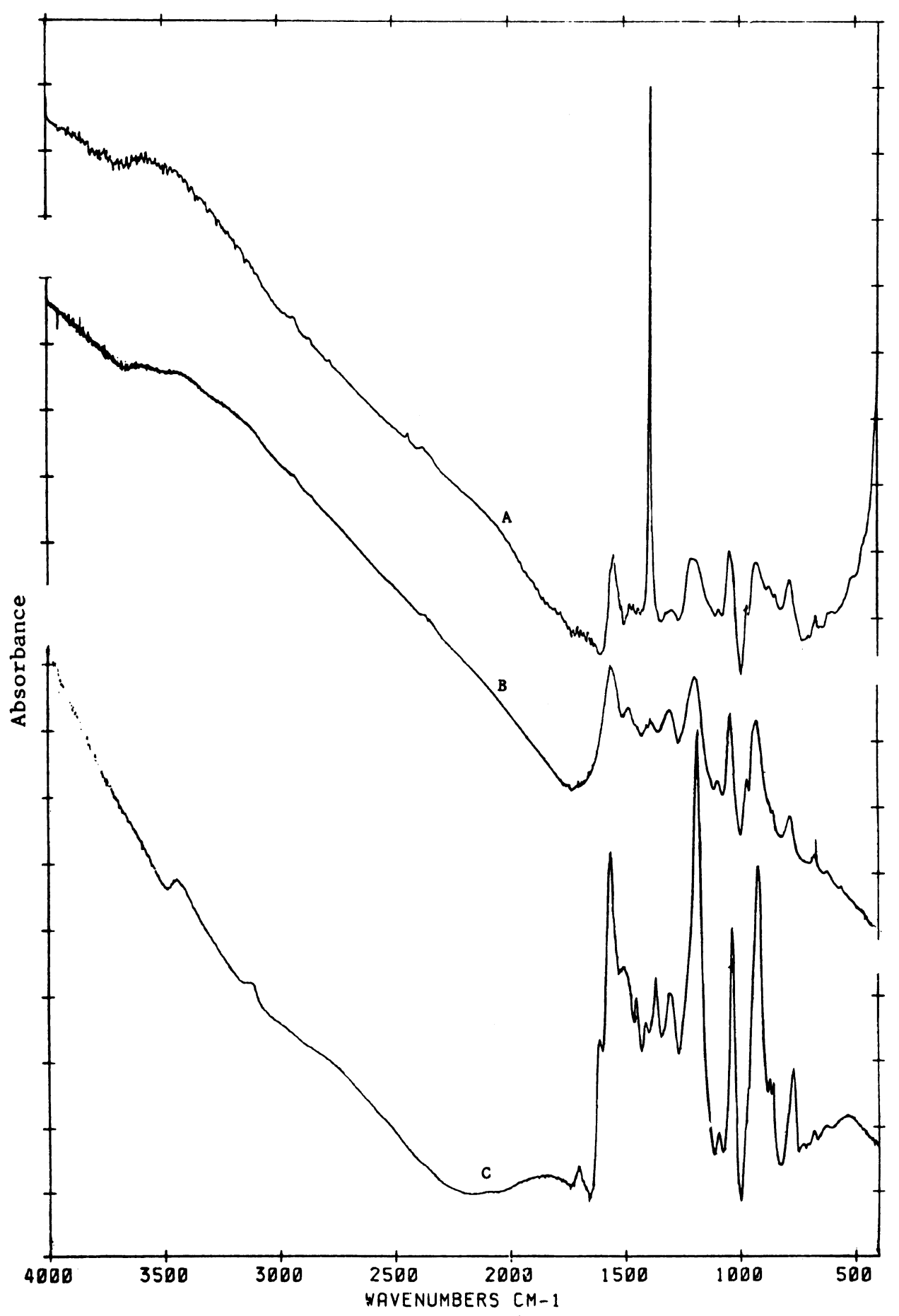

Figure 12. IR spectra of (A) $\mathrm{NO}_{3}^{-}$intercalated PPy film; (B) the film A after treatment with $2 \mathrm{M} \mathrm{NaOH}$ solution for $6 \mathrm{~h} ;(\mathrm{C})$ the film $\mathrm{A}$ after electrochemical reduction. 
porting electrolyte. ${ }^{20,21}$ However, $\mathrm{ClO}_{4}^{-}$intercalated PPy film prepared in our laboratory from aqueous solution of $\mathrm{HClO}_{4}$ or $\mathrm{LiClO}_{4}$ does show the absorption bands at 627,1120 , and $1145 \mathrm{~cm}^{-1}$ attributed to $\mathrm{ClO}_{4}^{-}$(vide infra).

When a $\mathrm{NO}_{3}^{-}$intercalated PPy film is reduced electrochemically in a $0.1 \mathrm{M} \mathrm{NaNO}_{3}$ solution at $-0.8 \mathrm{~V}$ vs. SCE to a conductivity of $10^{-6} \mathrm{~S} \mathrm{~cm}^{-1}$ or less, the reduced film gives much sharper and well resolved IR spectrum with no absorption at $1384 \mathrm{~cm}^{-1}$ as shown in Figure 12. This indicates clearly that the counter anion $\mathrm{NO}_{3}^{-}$has been de-intercalated during the electrochemical reduction process. On the other hand when a $\mathrm{TsO}^{-}$intercalated PPy film is electrochemically reduced in a

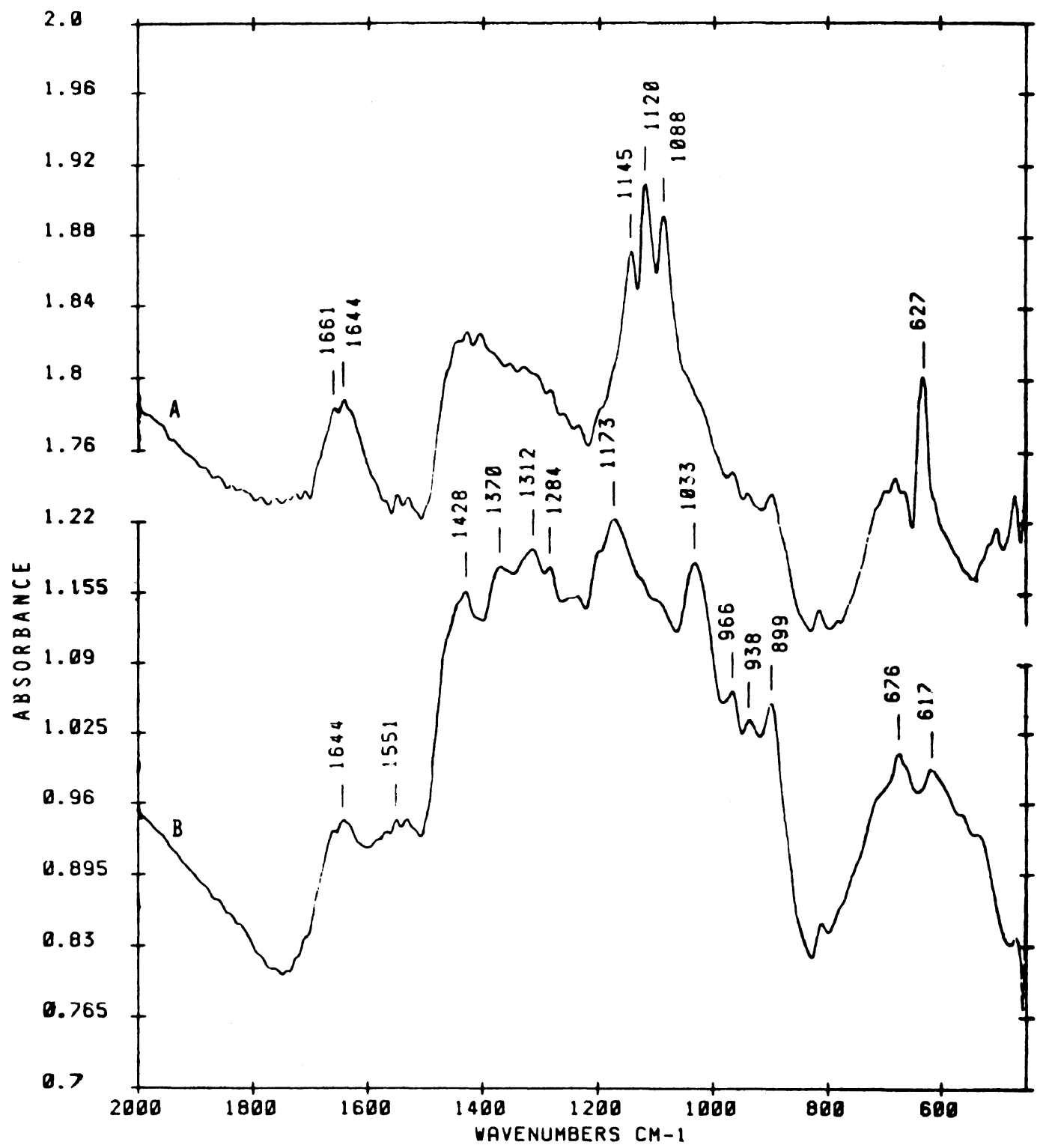

Figure 13. IR spectra of (A) a $\mathrm{ClO}_{4}^{-}$intercalated PPy film; (B) the film $\mathrm{A}$ after electrochemical reduction. 
$0.1 \mathrm{M} \mathrm{NaNO}_{3}$ solution and then re-oxidized electrochemically at $+0.4 \mathrm{~V} v s$. SCE, the film after thorough washing shows clearly the presence of $1384 \mathrm{~cm}^{-1}$ absorption. As there are much more $\mathrm{NO}_{3}^{-}$ions in the solution during re-oxidation than $\mathrm{TsO}^{-}$ions de-intercalated from reduction of the starting film, the counter anions re-intercalated into the film during re-oxidation must naturally $\mathrm{NO}_{3}^{-}$ instead of $\mathrm{TsO}^{-}$. These facts demonstrate without any ambiguity that the processes involved in the electrochemical oxidation ("doping") and reduction ("de-doping") are actually charge transfer intercalation and de-

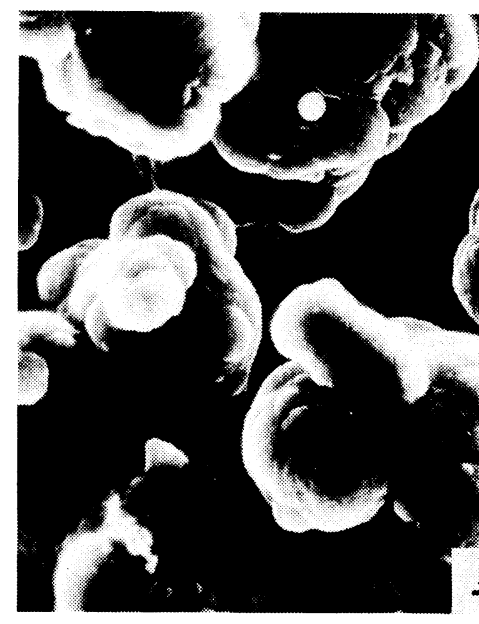

a

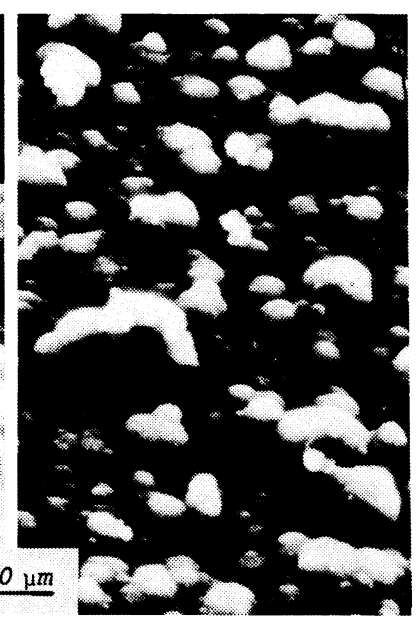

b

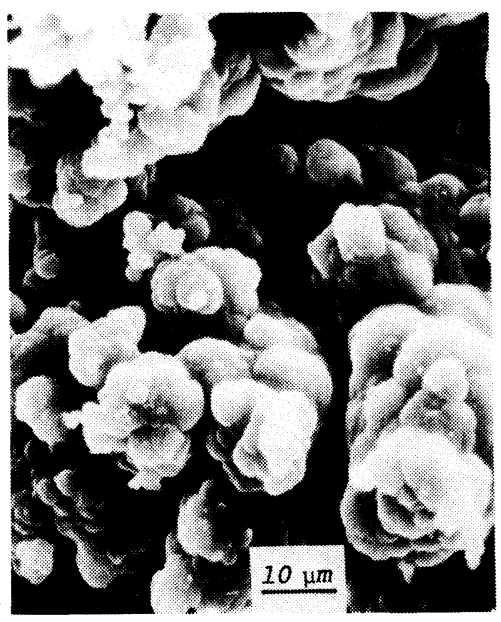

c

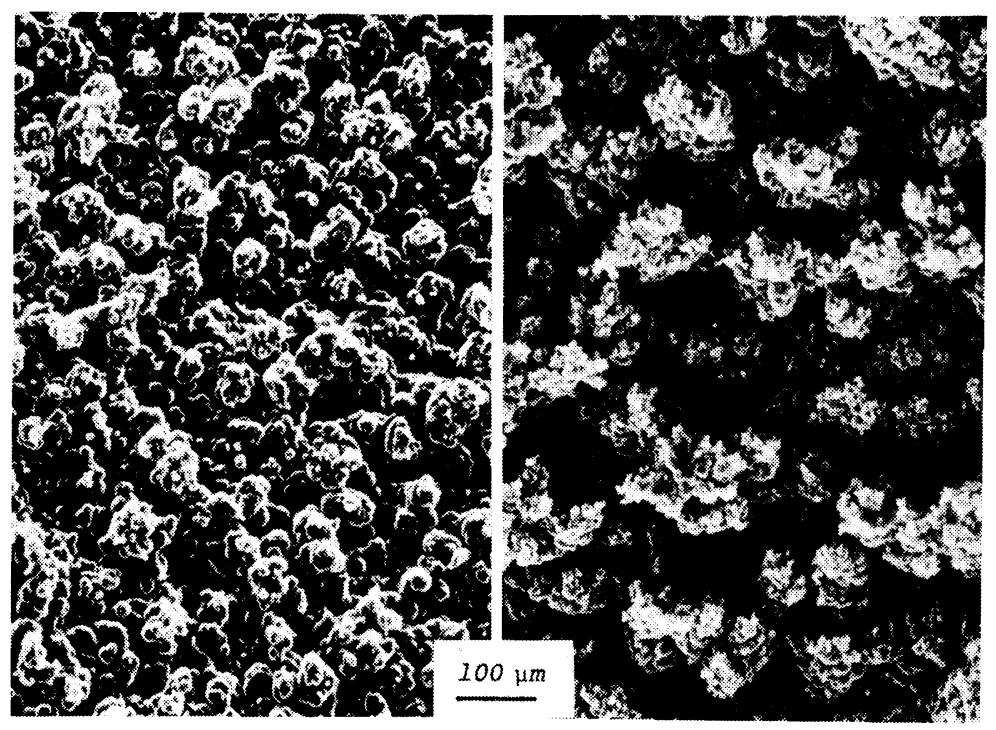

d

e

Figure 14. SEM photographs of (a) a $\mathrm{TsO}^{-}$intercalated PPy film; (b) the film after electrochemical reduction; (c) the film after electrochemical re-oxidation; (d) and (e) the same as (a) and (c) respectively at lower magnification. 
intercalation of the counter ions in the PPy film. ${ }^{8}$ By intercalation here it does not necessary mean the incorporation of the counter ions between lattice planes, as PPy is in fact amorphous, but between chains in the macromolecular condensed state. Kaufman et $a l .{ }^{18}$ deduced from their electrochemical voltage spectroscopy that during electrochemical reduction of a $\mathrm{ClO}_{4}^{-}$intercalated $\mathrm{PPy}$ film in a THF solution of $\mathrm{LiClO}_{4}$ the process involved is not the de-intercalation of $\mathrm{ClO}_{4}^{-}$ anion but the intercalation of $\mathrm{Li}^{+}$cation leading to a compensation of charges. This statement is very probably not true. We electrochemically reduced a $\mathrm{ClO}_{4}^{-}$intercalated PPy film in an aqueous solution of $\mathrm{LiClO}_{4}$, the IR spectra of the film before and after reduction show clearly the presence and absence respectively of the absorption bands at $627 \mathrm{~cm}^{-1}$ and at $1120,1145 \mathrm{~cm}^{-1}$ characteristic of the $\mathrm{ClO}_{4}^{-}$ion as shown in Figure 13. Only in the case of a polymeric counter anion like polyvinyl sulfate intercalated PPy film it has been found by Iyoda et al. ${ }^{5}$ that during electrochemical reduction in a solution of $\mathrm{K}$ salt of polyvinyl sulfate the polymeric counter anions are not de-intercalated but $\mathrm{K}^{+}$cations go into the film instead.

Treatment of a conducting PPy film with $\mathrm{NaOH}$ or $\mathrm{NH}_{4} \mathrm{OH}$ solution leads to an enormous drop of its conductivity, from $10^{2} \mathrm{~S} \mathrm{~cm}^{-1}$ dropping to $10^{-4} \mathrm{~S} \mathrm{~cm}^{-1}$. This has been termed chemical compensation. The IR spectrum of a $\mathrm{NO}_{3}^{-}$intercalated PPy film after being immersed in $2 \mathrm{M} \mathrm{NaOH}$ solution for $6 \mathrm{~h}$ shows the absence of the $\mathrm{NO}_{3}^{-}$counter anion as shown also in Figure 12. Judging from the conductivity value being still two orders of magnitude higher than that of an electrochemically reduced film and the broadness of the absorption bands resembling an intercalated film we suppose that there may be residual charged defects in the PPy chain due to incompleteness of de-intercalation or very probably due to $\mathrm{OH}^{-}$intercalation.

SEM observation of a $\mathrm{TsO}^{-}$intercalated PPy film and the film after electrochemical reduction and re-oxidation reveals profound morphological changes occurring in these processes as shown in Figure 14. This indicates a

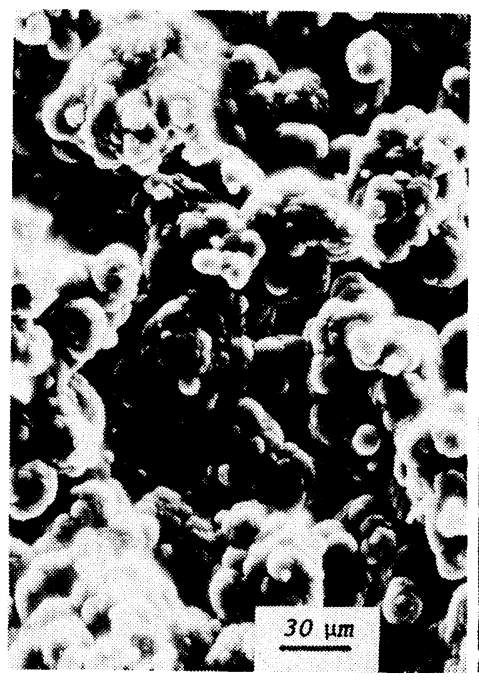

a

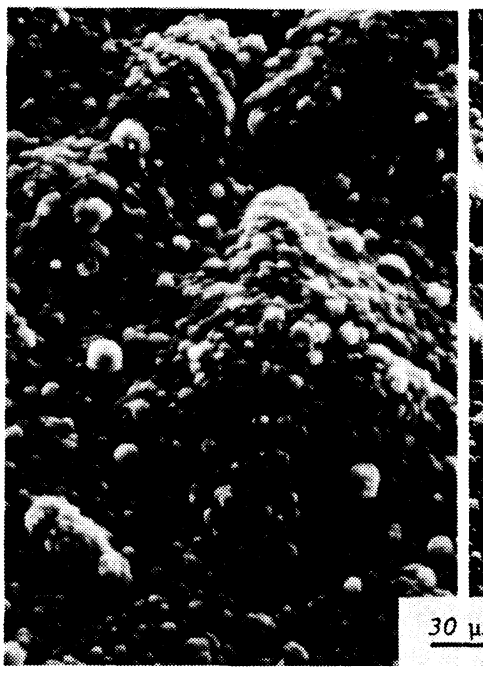

b

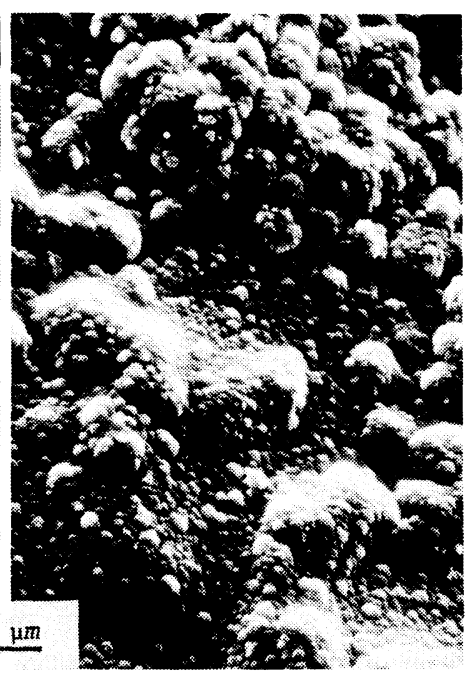

c

Figure 15. SEM photographs of (a) a $\mathrm{NO}_{3}^{-}$intercalated PPy film; (b) the film after electrochemical reduction; (c) the film after electrochemical re-oxidation. 
disruption and re-organization of the macromolecular aggregation in the solid state during these processes. ${ }^{8}$ Similar results are obtained for $\mathrm{NO}_{3}^{-}$intercalated PPy as shown in Figure 15. These results seem to support the view of chemical structural change during reduction and re-oxidation discussed in the previous section, as analogous observations on intercalated polythiophene film show no significant changes in morphology during electrochemical reduction and re-oxidation. ${ }^{22}$

\section{MOLECULAR COMPOSITE}

Fiber reinforced plastics have been widely used as strong and light weight materials as metal substitutes. The idea of improving mechanical properties of a flexible chain polymer by dispersing in it a fibre of large aspect ratio has led to the development of "molecular composite" by Takayanagi ${ }^{23}$ and by Helminiak ${ }^{24}$ using methods of co-precipitation and block co-polymerization to disperse a rigid rod-like macromolecule of large intrinsic aspect ratio in a matrix of flexible chain polymer. Although the dispersion achieved has so far not been able to reach truly molecular level, very attractive results have been obtained in getting a light weight, high modulus, high strength and heat resistant material comparable in mechanical properties of aluminum. ${ }^{25}$ Conducting polymers are conjugated chain macromolecules which are expected to behave as rigid rods. Graft-block copolymers of polyacetylene onto polyisoprene $^{26}$ and polybutadiene ${ }^{27}$ are soluble conducting polymers and belong to the category of molecular composite. A more promising way of preparing a molecular composite of conducting polymers is to polymerize in situ acetylene, pyrrole, thiophene etc. in a flexible polymer matrix. Wnek ${ }^{28}$ impregnated LDPE film with a catalyst solution to polymerize acetylene gas in the film and a flexible film of conductivity $10 \mathrm{~S} \mathrm{~cm}^{-1}$ resulted. For a PPy molecular composite the in situ polymerization of pyrrole in a flexible polymer film can be carried out either electrochemically or chemically. Electrochemical growth of intercalated PPy in lightly crosslinked polyvinyl alcohol ${ }^{29}$ and polyvinyl chloride ${ }^{30}$ films on $\mathrm{Pt}$ electrode from aqueous and acetonitrile solution respectively has been successfully conducted to give composite polymer films of conductivities of $10^{-1}$ to $10 \mathrm{~S} \mathrm{~cm}^{-1}$. Chemical polymerization of $\mathrm{pyr}-$ role by persulfate, ceric sulfate and Lewis acids like $\mathrm{FeCl}_{3}, \mathrm{MoCl}_{5}$, and $\mathrm{RuCl}_{3}$ can be utilized for the preparation of molecular composites of PPy with commonly available flexible polymers. The flexible polymer film is swollen with solvent containing the polymerization catalyst and then the film is exposed to pyrrole vapor resulting in the in situ polymerization. ${ }^{31-33}$ In the other way the flexible polymer film can be swollen with a solvent containing pyrrole and then the film is brought in contact with the polymerization catalyst solution to carry out the in situ polymerization of pyrrole in the film. ${ }^{34}$ Chemically polymerized and intercalated PPy powder can be mechanically incorporated into plastics to give molded composites ${ }^{35}$ but probably not in the proper sense of a molecular composite. Or, polymeric electrolytes like polystyrene sulfonate or polyvinyl sulfate $^{5}$ and sulfonated SBS triblock with the B block hydrogenated, ${ }^{6}$ used as the supporting electrolyte during electrochemical polymerization of pyrrole can also lead to molecular composites of PPy. All these molecular composites of PPy can have a conductivity ranging from $10^{-3}$ to $10 \mathrm{~S} \mathrm{~cm}^{-1}$.

In our laboratory we have been able to prepare molecular composites of PPy with a wide variety of commercial plastics like Nylon, PVC, PVA, PVAc, polyvinyl butyral, amorphous PET, cellophane, viscose, cellulose, cotton, wool, natural rubber, Nafion film etc. through in situ polymerization of pyrrole imbibed in the polymer film or fiber with a proper solvent. ${ }^{36}$ The bulk conductivity (not the sur- 

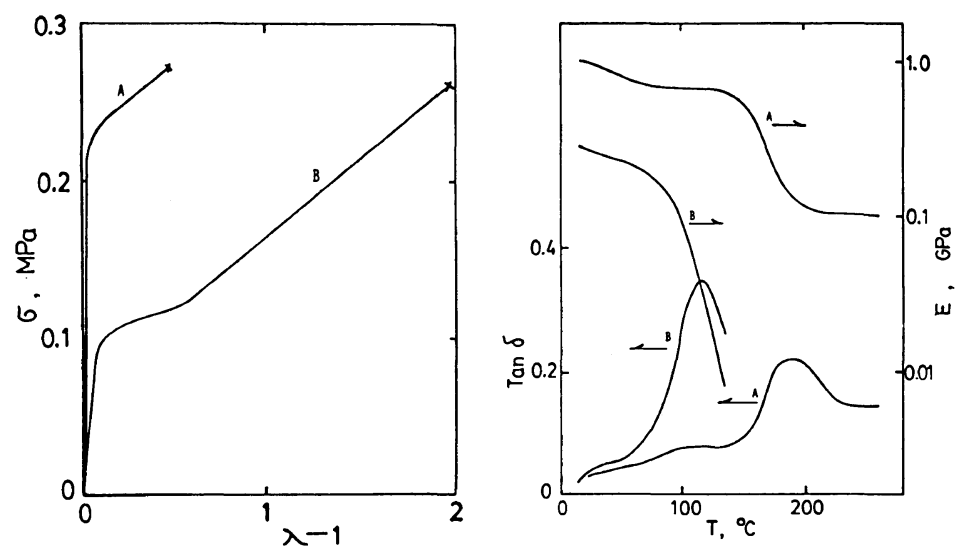

Figure 16. Stress strain behavior under stretching at $80 \%$ per min (left) and dynamic mechanical properties (right) of PPy/Nafion composite (A) as compared to Nafion film (B).

face conductivity) can be controlled by the polymerization condition to vary from $10^{-9}$ to $10^{-2} \mathrm{~S} \mathrm{~cm}^{-1}$. The low conductivity of a PPy/ Nafion composite has been shown to have an island and sea morphology with PPy domains of $80 \mathrm{~nm}$ diameter. ${ }^{34}$ These PPy molecular composites are potential materials for antistatic applications. PPy composites with conductivities higher than $10 \mathrm{~S} \mathrm{~cm}^{-1}$ may find applications in EMI shielding. The incorporation of rigid chain PPy into a flexible polymer does actually show a several fold increase of modulus with decrease of the extension at break as examplified in Figure $16,{ }^{34}$ and render the plastics hydrophobic.

Molecular composites of conducting polymers are new class of materials with wide range of potential applications. A rapid development in this area is to be expected.

Acknowledgement. This work was supported by the Science Fund of Academia Sinica. Throughout the work we are indebted to many colleagues for help in numerous ways.

\section{REFERENCES}

1. A. Dall'Olio, G. Dascola, V. Varacca, and V. Bocche, Compt. rend. l'Acad. Sci. (Paris), C267, 433 (1968).

2. A. F. Diaz, K. K. Kanazawa, and G. P. Gardini, J.
Chem. Soc., Chem. Commun., 635 (1979).

3. W. Wernet, M. Monkenbusch, and G. Wegner, Mol. Cryst. Liq. Cryst., 118, 193 (1985).

4. M. Satoh, K. Kaneto, and K. Yoshino, Jpn. J. Appl. Phys., 24, L423 (1985).

5. T. Iyoda, A. Ohtani, T. Shimidzu, and K. Honda, Chem. Lett., 687 (1986).

6. N. Bates, M. Cross, R. Lines, and D. Walton, $J$. Chem. Soc., Chem. Commun., 871 (1985).

7. X. Bi, Y. Yao, M. Wan, P. Wang, K. Xiao, Q. Yang, and R. Qian, Makromol. Chem., 186, 1101 (1985).

8. R. Qian, J. Qiu, and D. Shen, Abstr. ICSM 86, p 308; Synth. Met., in press.

9. J. Qiu, M. S. thesis, Institute of Chemistry, Academia Sinica, 1986.

10. R. Qian, J. Qiu, and B. Yan, Synth. Met., 14, 81 (1986).

11. S. Asavapiriyanont, G. K. Chandler, G. A. Gunawardena, and D. Pletcher, J. Chem. Soc., Chem. Commun., 871 (1985).

12. N. F. Mott and E. A. Davis, "Electronic Processes in Non-Crystalline Materials," 2nd ed, Clarendon Press, Oxford, 1979, p 34.

13. Y. Shen, K. Carneiro, C. Jacobsen, R. Qian, and J. Qiu, Abstr. ICSM 86, p 209; Synth. Met., in press.

14. L. B. Coleman, Rev. Sci. Instru., 49, 58 (1978).

15. M. Wan, D. Zhu, M. Li, and R. Qian, Kexue Tongbao, 28, 1623 (1983).

16. M. Wan, P. Wang, Y. Cao, F. Wang, X. Zhao, and Z. Gong, Solid State Commun., 47, 759 (1983).

17. P. Wang, M. Wan, X. Bi, Y. Yao, and R. Qian, Acta Phys. Sin., 33, 1771 (1984).

18. J. H. Kaufman, K. K. Kanazawa, and G. B. Street, Phys. Rev. Lett., 53, 2461 (1984).

19. R. Jones and G. P. Beau, "The Chemistry of Pyrroles," Academic Press, New York, N. Y., 1977, p 117. 


\section{R. QIAN and J. QIU}

20. G. B. Street, T. C. Clarke, M. Krounbi, K Kanazawa, V. Lee, P. Pfluger, J. C. Scott, and G. Weiser, Mol. Cryst. Liq. Cryst., 83, 253 (1982).

21. L. Oddi, R. Capelletti, R. Fiescher, M. P. Fontana, G. Ruani, V. Bocchi, and G. P. Gardini, Mol. Cryst. Liq. Cryst., 118, 179 (1985).

22. Y. Cao and H. Zhang, private communication.

23. M. Takayanagi, Japan Patent appl. S52-131436 (1977); U. S. Patent appl. 958324 (1978); Pure Appl. Chem., 55, 819 (1983).

24. T. E. Helminiak, U. S. Patent appl. 902525 (1978).

25. W. W. Adams, T. E. Helminiak, and A. Visvanathan, Proceedings, IUPAC MACRO 82, 1982, p 828.

26. F. S. Bates and G. I. Baker, Maceomolecules, 16, 704 (1983).

27. S. Destri, M. Calellani, and A. Bolognesi, Makromol. Chem., Rapid Commun., 5, 353 (1984).

28. G. E. Wnek, Proceedings, IUPAC MACRO 82, 1982, p 409; U. S. Patent appl. 4394304 (1982).
29. S. E. Lindsey and G. B. Street, Synth. Met., 10, 67 (1984).

30. O. Niwa and T. Tamamura, J. Chem. Soc., Chem. Commun., 817 (1984).

31. A. Pron, B. Raynor, P. Bernier, S. Lefrant, W. Fabianowski, and C. Budrowski, Abstr. ICSM 86, 1986, p 177.

32. R. Sugimoto, H. B. Gu, S. Hayashi, and K. Yoshino, Abstr. ICSM 86, 1986, p 192.

33. S. Miyata, T. Ojio, and Y. E. Wang, Abstr. ICSM 86, 1986, p 427.

34. R. Qian and Y. Chen, Proceedings, Plastics Conference, The Plastics \& Rubber Institute, Singapore, 1986.

35. G. P. Gardini and V. Bocchi, Abstr. ICSM 86, 1986, p 194.

36. Institute of Chemistry, Academia Sinica, Chinese Patent appl. 86101389 (1986). 